\title{
Black Tea Exhibits a Dose-Dependent Response in Saos-2 Cell Mineralization
}

\author{
Riley E. Cleverdon, ${ }^{1,2}$ Michael D. McAlpine, ${ }^{1,2}$ and Wendy E. Ward ${ }^{1,2}$ \\ ${ }^{1}$ Department of Kinesiology and ${ }^{2}$ Centre for Muscle and Bone Health, Faculty of Applied Health Sciences, \\ Brock University, St. Catharines, ON, Canada.
}

\begin{abstract}
Higher bone mineral density (BMD) is often associated with greater consumption of black tea (BT). However, the dose-response of BT on mineralization in an osteoblast cell model has not yet been studied. The study objective was to determine the dose-dependent response of BT in Saos-2 cells and investigate changes to several proteins involved in the mineralization process. Mineralization was induced in the presence of BT at concentrations that represent levels likely achieved through daily consumption $(0.1,0.5,0.75,1 \mu \mathrm{g}$ gallic acid equivalents $[\mathrm{GAE}] / \mathrm{mL})$ or through supplementation $(2,5$, or $10 \mu \mathrm{g} \mathrm{GAE} / \mathrm{mL})$. BT exerted a positive dose-response on bone mineralization, peaking at $1 \mu \mathrm{g} \mathrm{GAE} / \mathrm{mL}$ of BT $(P<.05)$. Cellular activity was significantly greater than control with exposure to $2-10 \mu \mathrm{g} \mathrm{GAE} / \mathrm{mL}$ of BT (at $24 \mathrm{~h})(P<.05)$ and $1-10 \mu \mathrm{g} \mathrm{GAE} / \mathrm{mL}$ (at $48 \mathrm{~h})(P<.05)$, with a peak at $5 \mu \mathrm{g} \mathrm{GAE} / \mathrm{mL}$ at 24 and $48 \mathrm{~h}(P<.05)$. Protein expression of alkaline phosphatase and ectonucleotide pyrophosphatase/phosphodiesterase-1 were unchanged, whereas a moderate dose of BT $(0.75 \mu \mathrm{g} \mathrm{GAE} / \mathrm{mL})$ resulted in greater expression of osteopontin compared with the highest dose $(10 \mu \mathrm{g} \mathrm{GAE} / \mathrm{mL})(P<.05)$. Doses of BT from 0.5 to $10 \mu \mathrm{g} \mathrm{GAE} / \mathrm{mL}$ resulted in higher antioxidant capacity compared with control $(P<.05)$. In summary, the higher antioxidant capacity, enhanced cell viability, and upregulated mineralization suggest that consumption of BT may have a positive effect on BMD at levels obtained through consumption of tea.
\end{abstract}

\section{KEYWORDS: • antioxidant $\bullet$ bone $\bullet$ cell culture $\bullet$ nutrition $\bullet$ osteoblast $\bullet$ tea}

\section{INTRODUCTION}

$\mathbf{F}$ INDINGS FROM PROSPECTIVE and cross-sectional studies, mostly in postmenopausal women, suggest a positive association between habitual tea drinking and higher bone mineral density (BMD) ${ }^{1-7}$ In a prospective study of older women ( $>75$ years old) who were at risk of fracture, habitual consumption of three or more cups of black tea (BT) per day was associated with a $30 \%$ reduction in fracture risk. ${ }^{2}$ There is a paucity of data in men with two studies showing no association and another study showing a positive association between higher tea intake and higher BMD. ${ }^{1,6,8}$ Whole BT $(0.05 \mathrm{~g} / \mathrm{mL})$ has shown positive effects on bone histomorphometry, strength, and BMD in ovariectomized female rat models. ${ }^{9,10}$ The levels of BT in the aforementioned studies are steeped at concentrations of tea similar to dietary consumption. ${ }^{9-11}$ In vitro models have shown that providing BT can enhance mineralization in Saos-2 osteoblast cells,

Manuscript received 8 January 2020. Revision accepted 30 January 2020.

Address correspondence to: Wendy E. Ward, BSc (Hons), MSc, PhD, Department of Kinesiology, Faculty of Applied Health Sciences, Brock University, 1812 Sir Isaac Brock Way, St. Catharines L2S 3A1, ON, Canada, E-mail: wward@brocku.ca

C Riley E. Cleverdon et al. 2020; Published by Mary Ann Liebert, Inc. This Open Access article is distributed under the terms of the Creative Commons Attribution Noncommercial License (http://creativecommons.org/licenses/by-nc/4.0/) which permits any noncommercial use, distribution, and reproduction in any medium, provided the original author(s) and the source are cited. whereas decreasing cell toxicity and increasing cellular activity at a dose of $1 \mu \mathrm{g}$ gallic acid equivalents (GAE) $/ \mathrm{mL} .{ }^{12}$ However, there is a paucity of information on an optimal dose of BT to stimulate bone mineralization. The objective of this study was to determine if BT has a dose-dependent effect on mineral production as well as elucidating what key proteins may be involved. It was hypothesized that BT would exert a positive effect on Saos- 2 cell mineralization in a dose-dependent manner but would exhibit negligible increases in mineralization as the dose reaches the highest concentrations tested. Previously, a supplemental dose of BT (10 $\mu \mathrm{g} \mathrm{GAE} / \mathrm{mL}$ in Saos-2 cells) was not shown to stimulate mineralization, likely due to BT having pro-oxidant effects at this high dose. ${ }^{12}$

\section{METHODS, RESULTS, AND DISCUSSION}

Experiments using Saos-2 cells were conducted between passages 60 and 90 . All experiments were analyzed with oneway ANOVA (Prism V5, La Jolla, CA, USA). Tukey's post hoc analysis determined differences among specific groups, $P<.05$. Results are reported as mean (\% of control) \pm SEM.

To ensure consistency, a single batch of loose-leaf English Breakfast BT from a specialty tea shop was used. BT $\left(200 \mathrm{mg}\right.$ ) was steeped in $\mathrm{dH}_{2} \mathrm{O}(5 \mathrm{~mL})$ for $3 \mathrm{~min}$ to extract whole tea according to manufacturer recommendations. TPC was measured with Folin-Ciocalteau's methodology (ISO 14502-1:2005) with a gallic acid standard to determine 
GAE. ${ }^{12-14}$ Differing concentrations of BT according to TPC were measured at $0.1,0.5,0.75,1,2,5$, and $10 \mu \mathrm{g} \mathrm{GAE} / \mathrm{mL}$. Concentrations of $0.1-1 \mu \mathrm{g}$ GAE $/ \mathrm{mL}$ are likely relatable to consuming two to three cups of BT per day. Higher doses ( $\geq 2 \mu \mathrm{g} \mathrm{GAE} / \mathrm{mL}$ ) are representative of levels of polyphenols attained through supplementation or consumption of large quantities of tea ( $>10$ cups per day). ${ }^{15}$

The free radical 2,2-diphenyl-1-picrylhydrazyl (DPPH) was used to measure the scavenging ability (representing potential antioxidant capacity [PAC]) of BT. The PAC of BT doses of $0.1-10 \mu \mathrm{g}$ GAE/mL were tested by scavenging DPPH using a previously determined methodology. ${ }^{13,16} \mathrm{BT}$ concentrations of $0.5-10 \mu \mathrm{g}$ GAE $/ \mathrm{mL}$ resulted in significantly greater inhibition of DPPH than control $(P<.05)$. A significant difference in DPPH inhibition was seen between each BT concentration except between 0.5 and
$0.75 \mu \mathrm{g} \mathrm{GAE} / \mathrm{mL}$ and between 5 and $10 \mu \mathrm{g} \mathrm{GAE} / \mathrm{mL}$, respectively (Fig. 1a).

Cellular viability was measured through cellular activity using the 3-(4,5-dimethylthiazol-2-yl)-2,5-diphenyltetrazolium bromide (MTT) assay after 24 and $48 \mathrm{~h}$ of cell exposure to BT $(0.1,0.5,0.75,1,2,5$, or $10 \mu \mathrm{g} \mathrm{GAE} / \mathrm{mL})$ or control vehicle. ${ }^{17,18}$ After $24 \mathrm{~h}$, Saos-2 cells displayed a significantly higher cellular activity $(P<.05)$ at concentrations $2-10 \mu \mathrm{g}$ GAE/mL. There was a dose-dependent response of BT doses at $24 \mathrm{~h}$ (CON, 0.1, 0.5, 0.75, 1, 2, 5, $10 \mu \mathrm{g} \mathrm{GAE} / \mathrm{mL}$ ). After $48 \mathrm{~h}$, Saos2 cells had a significantly higher cellular activity than control $(P<.05)$ at BT concentrations $1-10 \mu \mathrm{g}$ GAE $/ \mathrm{mL}$. There was also a dose-dependent response at $48 \mathrm{~h}(\mathrm{CON}, 0.1,0.5,0.75,1$, 2, 5, $10 \mu \mathrm{g} \mathrm{GAE} / \mathrm{mL}$ ) (Fig. 1c, d).

Saos-2 cells (American Type Tissue Culture, Manassas, VA, USA) were subcultured weekly in media $1 .{ }^{19}$ To measure
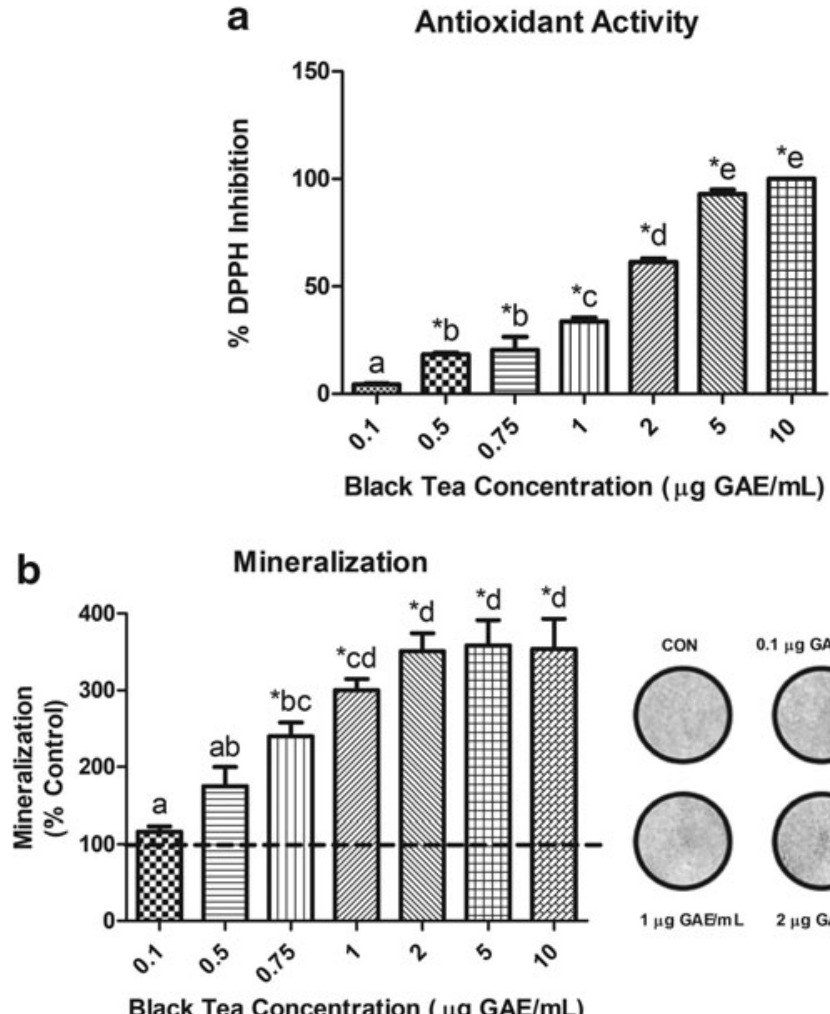

C

Cellular Activity at 24 Hours

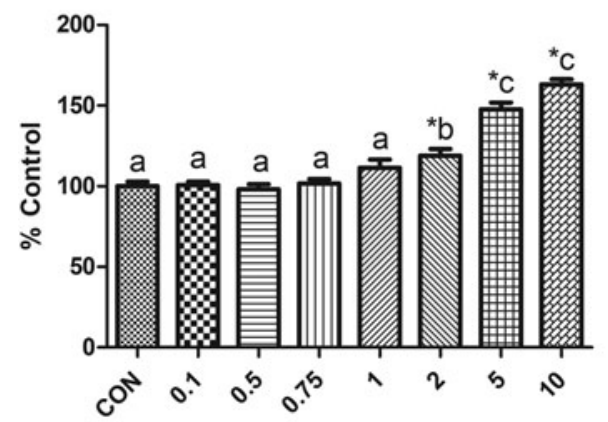

Black Tea Concentration ( $\mu \mathrm{g} \mathrm{GAE} / \mathrm{mL}$ )

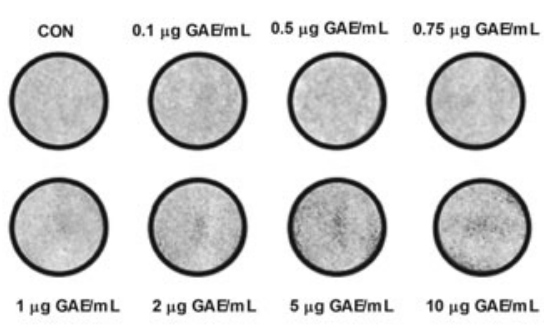

d Cellular Activity at 48 Hours

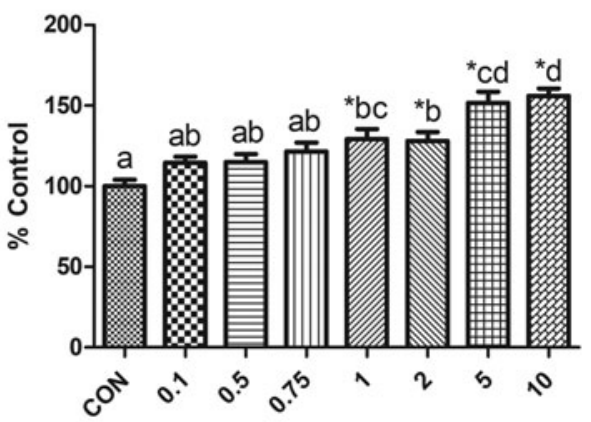

Black Tea Concentration ( $\mu \mathrm{g} \mathrm{GAE} / \mathrm{mL}$ )
FIG. 1. BT's effect on Saos-2 cells. All data are expressed as mean \pm SEM. * indicates a significant difference $(P<.05)$ between control and BT concentration, whereas differing letters indicate a significant difference $(P<.05)$ between $\mathrm{BT}$ concentrations. (a) Ability of BT to scavenge DPPH $(n=4)$. (b) Mineralization after 5 days in the absence or presence of differing concentrations of BT, $n=6$ (each sample was the resulting average of three wells). Graphs (c) and (d) show cellular viability through cellular metabolism observed in control and tea conditions after $24(n=12)$ and $48 \mathrm{~h}(n=12)$ of exposure to MTT, respectively. * indicates a significant difference $(P<.05)$ between control and BT concentration, whereas differing letters indicate a significant difference $(P<.05)$ between BT concentrations. BT, black tea; DPPH, 2,2-diphenyl-1-picrylhydrazyl; MTT, 3-(4,5-dimethylthiazol-2-yl)-2,5diphenyltetrazolium bromide. 
mineralization and protein expression, cells were plated in 24well plates in media 2 and replenished every $72 \mathrm{~h}$ for 8 days to allow for differentiation. ${ }^{19}$ Cells were then introduced to media 3 in the presence of BT concentrations of $0.1-10 \mu \mathrm{g}$ $\mathrm{GAE} / \mathrm{mL}$ or $\mathrm{dH}_{2} \mathrm{O}$ control. ${ }^{19}$ Media was changed every other day until day 14, where cells were washed with phosphatebuffered saline. To prepare cells for mineralization, cells were fixed in $4 \%$ paraformaldehyde and stored overnight at $4^{\circ} \mathrm{C}$. To extract proteins for expression, cells were lysed with radioimmunoprecipitation assay buffer containing phosphatase (PhosSTOP) and protease (cOmplete) inhibitors.

To quantify mineralization, an alizarin red assay was conducted on day 14 (day 5 of mineralization). ${ }^{12,19} 150 \mu \mathrm{L}$ aliquots of cell-stain mixture from each condition were measured in triplicate at an optical density of $550 \mathrm{~nm}$ to quantify staining. Cells treated with BT $(0.75-10 \mu \mathrm{g} \mathrm{GAE} / \mathrm{mL})$ resulted in a significantly greater mineralization content than control $(P<.05)$. No significant difference was observed between control, 0.1 and $0.5 \mu \mathrm{g} \mathrm{GAE} / \mathrm{mL}$ of BT. A concentration of $10 \mu \mathrm{g} \mathrm{GAE} / \mathrm{mL}$ did not have significantly different mineralization from concentrations of $1-5 \mu \mathrm{g} \mathrm{GAE} / \mathrm{mL}$ of BT (Fig. 1b).

Expression of proteins of interest (alkaline phosphatase [ALP], osteopontin [OPN], ectonucleotide pyrophosphatase/ phosphodiesterase-1 [NPP1]) was determined at day 3 of mineralization through immunoblotting using a previously established protocol ${ }^{17}$ Differences in the protocol included use of either a $0.2 \mu \mathrm{m}$ polyvinylidene difluoride membrane (ALP and NPP1) or nitrocellulose membrane (OPN). Primary antibodies included ALP: 1:1000 (ab108337), 5\% BSA/TBST; NPP1: 1:1000 (ab217368), 5\% BSA/TBST; OPN: 1:1000 (ab33046), and 5\% milk/TBST. The secondary antibody used

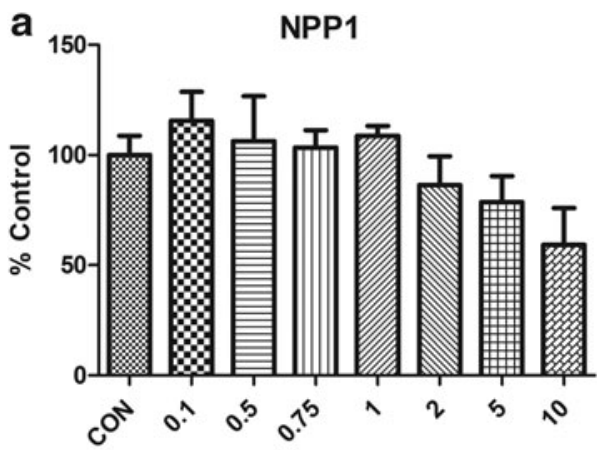

Black Tea Concentration ( $\mu \mathrm{g} \mathrm{GAE} / \mathrm{mL}$ )

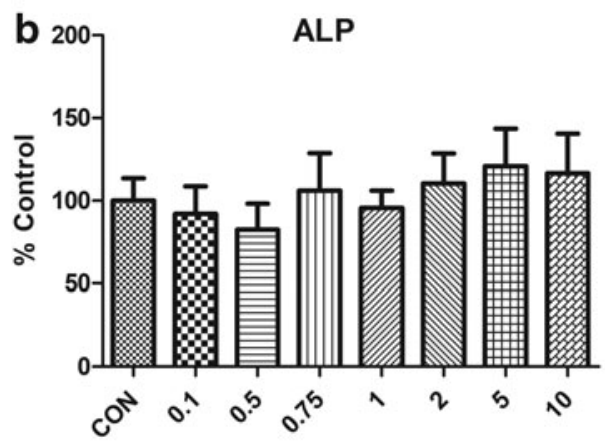

Black Tea Concentration ( $\mu \mathrm{g} \mathrm{GAE} / \mathrm{mL}$ )

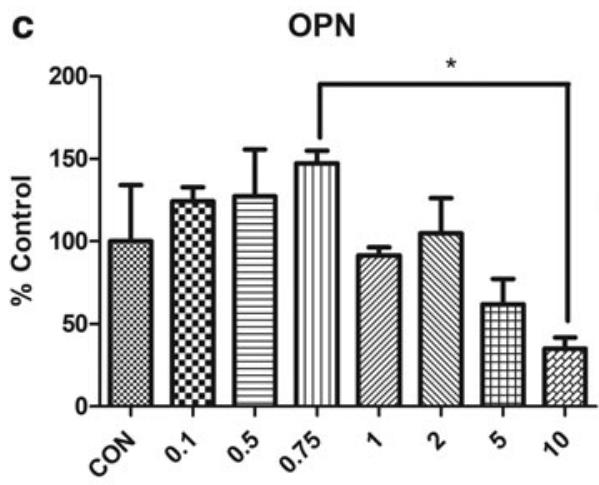

Black Tea Concentration ( $\mu \mathrm{g} \mathrm{GAE} / \mathrm{mL}$ )

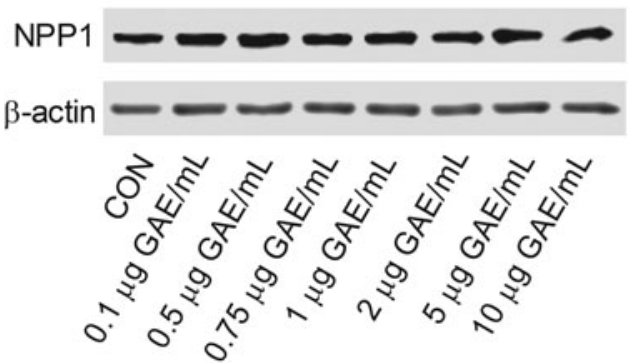

FIG. 2. Influence of BT concentration on protein expression in Saos-2 cells. Mineralization after 3 days in the absence or presence of differing concentrations of BT polyphenols were densitometrically analyzed for the expression of (a) NPP1 (b) ALP and (c) OPN. Images are representative images of protein expressions of NPP1, ALP, and OPN, respectively. Values are mean \pm SEM, $n=3$ (each sample was the resulting average of three wells). ALP, alkaline phosphatise; NPP1, ectonucleotide pyrophosphatase/phosphodiesterase1; OPN, osteopontin.

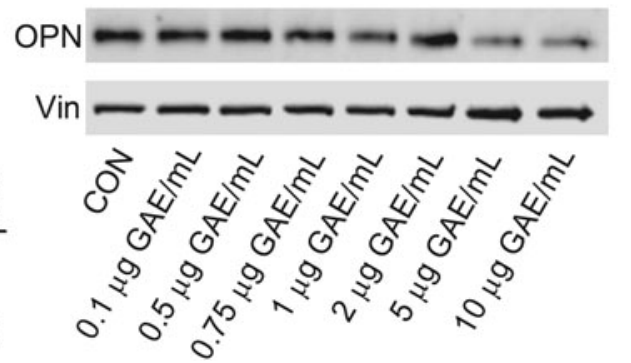


was 1:10000 (ab205718) in 5\% BSA/TBST (ALP and NPP1) or 5\% milk/TBST (OPN) (Abcam, Cambridge, UK). Protein signals were detected with the ChemiDoc Imaging System (Bio-Rad, Mississauga, ON, Canada) and densitometry analysis was performed using Image Studio Lite software (LICOR Biosciences, Lincoln, NE, USA). No significant difference in ALP and NPP1 expression in cells treated with BT (Fig. 2a, b). A BT concentration of $0.75 \mu \mathrm{g} \mathrm{GAE} / \mathrm{mL}$ resulted in significantly higher OPN expression than a BT concentration of $10 \mu \mathrm{g}$ GAE/mL (Fig. 2c).

Our findings support the hypothesis that mineralization in Saos- 2 cells increases with incremental BT doses but has negligible increases in mineralization as the dose reaches the highest concentrations that would be attained through supplementation. The current findings are similar to previous research that investigated a dietary $(1 \mu \mathrm{g} \mathrm{GAE} / \mathrm{mL})$ and supplemental dose $(10 \mu \mathrm{g} \mathrm{GAE} / \mathrm{mL})$ of BT. ${ }^{12}$ This may be due to antioxidant effects of BT at dietary levels of consumption. The optimal level of BT on bone mineralization $(\sim 1 \mu \mathrm{g} \mathrm{GAE} / \mathrm{mL})$, in vitro, is estimated to resemble the level in two to three cups of BT per day. Cell viability increased with moderate and high doses of BT at both $24 \mathrm{~h}$ (2-10 $\mu \mathrm{g}$ GAE $/ \mathrm{mL})$ and $48 \mathrm{~h}(0.1-10 \mu \mathrm{g}$ GAE $/ \mathrm{mL})$ of exposure, indicating that $\mathrm{BT}$ enhances the presence of viable mineral producing cells. Analysis of protein expression resulted in no change in expression of ALP-an indicator of bone formation or NPP1 - a regulator of bone mineralization. $^{20,21}$ Although ALP and NPP1 did not exhibit any changes in expression at day 3 of mineralization, it is unknown if the activity of these proteins was altered. A small but significant difference in expression of the mineralization inhibitor, OPN was seen between a mid-dose $(0.75 \mu \mathrm{g}$ $\mathrm{GAE} / \mathrm{mL})$ and the highest dose $(10 \mu \mathrm{g} \mathrm{GAE} / \mathrm{mL})$. Visual observation of analysis indicates a potential trend of decreased OPN expression at 5 and $10 \mu \mathrm{g} \mathrm{GAE} / \mathrm{mL}$; however, only $10 \mu \mathrm{g} \mathrm{GAE} / \mathrm{mL}$ was significant. Extremely high levels of BT may inhibit OPN but lowering its expression may not be associated with upregulating mineralization in Saos-2 cells. However, in a rodent model of ovariectomy, mice that were OPN deficient were protected from trabecular bone volume loss. ${ }^{22}$ As ovariectomy is often used as a model of postmenopausal osteoporosis, a link may exist between decreased OPN expression and decreased osteoporosis incidence.

At most concentrations of BT, there was a greater ability to scavenge DPPH than control. It is suspected that the polyphenolic compounds in BT, including the theaflavins play a role in the antioxidant abilities of BT. ${ }^{23}$ Saos- 2 cells can undergo apoptosis under conditions with high levels of reactive oxygen species (ROS) in a similar manner of osteoblasts and osteocytes in bone remodeling. ${ }^{24,25}$ Treatment with BT has been shown to decrease the levels of ROS, ${ }^{26}$ which may result in the presence of more viable cells to upregulate mineralization.

A limitation of this study was that whole BT was supplemented to cells instead of bioactive constituents that may reach the skeletal system in a physiological model. However, this in vitro model is a preliminary step in identifying the amount of BT to feed in vivo. A strength of this study includes being the first to study a large range of BT doses to determine the optimal dose-response in Saos-2 cells. A greater understanding of the optimal dose of $\mathrm{BT}$ in vitro may inform researchers of doses to investigate in preclinical and clinical models of bone health. Further research should determine if these doses of BT provide similar results in a preclinical animal model. In conclusion, we have shown that providing BT in vitro at levels attainable through dietary consumption of tea rather than supplementation can positively impact in vitro mineralization.

\section{AUTHOR DISCLOSURE STATEMENT}

No competing financial interests exist.

\section{FUNDING INFORMATION}

This research was supported by an NSERC Discovery Grant (W.E.W.), the Canada Research Chairs program (W.E.W.) and an NSERC USRA to R.E.C.

\section{REFERENCES}

1. Wu C-H, Yang Y-C, Yao W-J, Lu F-H, Wu J-S, Chang C-J: Epidemiological evidence of increased bone mineral density in habitual tea drinkers. Arch Intern Med (Online) 2002;162: 1001-1006.

2. Myers G, Prince RL, Kerr DA, et al.: Tea and flavonoid intake predict osteoporotic fracture risk in elderly Australian women: A prospective study. Am J of Clin Nutr (Online) 2015;102:958-965.

3. Hossein-nezhad A, Maghbooli Z, Shafaei A, Javadi E, Larijani B: Relationship between tea drinking and bone mineral density in Iranian population. Iranian J Publ Health 2007;36:57-62.

4. Hegarty VM, May HM, Khaw KT: Tea drinking and bone mineral density in older women. Am J Clin Nutr 2000;71:10031007.

5. Nash LA, Ward WE: Tea and bone health: Findings from human studies, potential mechanisms, and identification of knowledge gaps. Crit Rev Food Sci Nutr (Online) 2017;57:1603-1617.

6. Zhang ZQ, He LP, Liu YH, Liu J, Su YX, Chen YM: Association between dietary intake of flavonoid and bone mineral density in middle aged and elderly Chinese women and men. Osteoporos Int (Online) 2014;25:2417-2425.

7. Hoover PA, Webber CE, Beaumont LF, Blake JM: Postmenopausal bone mineral density: Relationship to calcium intake, calcium absorption, residual estrogen, body composition, and physical activity. Can J Physiol Pharmacol 1996;74:911917.

8. Li X, Qiao Y, Yu C, et al:: Tea consumption and bone health in Chinese adults: A population-based study. Osteoporos Int (Online) 2019;30:333-341.

9. Das AS, Mukherjee M, Mitra C: Evidence for a prospective antiosteoporosis effect of black tea (Camellia Sinensis) extract in a bilaterally ovariectomized rat model. Asia Pacific J Clin Nutr 2014;13:210-216.

10. Das AS, Mukherjee M, Das D, Mitra C: Protective action of aqueous black tea (Camellia sinensis) extract (BTE) against ovariectomy-induced oxidative stress of mononuclear cells and its associated progression of bone loss. Phytother Res (Online) 2009;23:1287-1294. 
11. Wei H, Zhang X, Zhao JF, Wang ZY, Bickers D, Lebwohl M: Scavenging of hydrogen peroxide and inhibition of ultraviolet light-induced oxidative DNA damage by aqueous extracts from green and black teas. Free Radic Biol Med (Online) 1999;26: 1427-1435.

12. Nash LA, Ward WE: Comparison of black, green and rooibos tea on osteoblast activity. Food Funct (Online) 2016;7:11661175 .

13. Cleverdon R, Elhalaby Y, McAlpine MD, Gittings W, Ward WE: Total polyphenol content and antioxidant capacity of tea bags: Comparison of black, green, red rooibos, chamomile and peppermint over different steep times. Beverages (Online) 2018;4:15.

14. Prior RL, Wu X, Schaich K: Standardized methods for the determination of antioxidant capacity and phenolics in foods and dietary supplements. J Agric Food Chem (Online) 2005;53:42904302.

15. Yang CS, Kim S, Yang GY, et al.: Inhibition of carcinogenesis by tea: Bioavailability of tea polyphenols and mechanisms of actions. Proc Soc Exp Biol Med (Online) 1999;220:213-217.

16. McAlpine MD, Ward WE: Influence of steep time on polyphenol content and antioxidant capacity of black, green, rooibos, and herbal teas. Beverages (Online) 2016;2:17.

17. McAlpine MD, Gittings W, MacNeil AJ, Ward WE: Red rooibos tea stimulates osteoblast mineralization in a dose-dependent manner. Beverages (Online) 2019;5:69.

18. Tada H, Shiho O, Kuroshima K, Koyama M, Tsukamoto K: An improved colorimetric assay for interleukin 2. J Immunol Methods (Online) 1986;93:157-165.
19. Nash LA, Sullivan PJ, Peters SJ, Ward WE: Rooibos flavonoids, orientin and luteolin, stimulate mineralization in human osteoblasts through the Wnt pathway. Mol Nutr Food Res (Online) 2015;59:443-453.

20. Okawa A, Nakamura I, Goto S, Moriya H, Nakamura Y, Ikegawa S: Mutation in Npps in a mouse model of ossification of the posterior longitudinal ligament of the spine. Nat Genet (Online) 1998;19:271-273.

21. van Straalen JP, Sanders E, Prummel MF, Sanders GTB: Bonealkaline phosphatase as indicator of bone formation. Clinica Chimica Acta (Online) 1991;201:27-33.

22. Yoshitake H, Rittling SR, Denhardt DT, Noda M: Osteopontindeficient mice are resistant to ovariectomy-induced bone resorption. Proc Natl Acad Sci (Online) 1999;96:8156-8160.

23. Rothwell JA, Urpi-Sarda M, Boto-Ordonez M, et al.: PhenolExplorer 2.0: A major update of the Phenol-Explorer database integrating data on polyphenol metabolism and pharmacokinetics in humans and experimental animals. Database (Online) 2012; 2012:bas031.

24. Bai X, Lu D, Liu A, et al.: Reactive oxygen species stimulates receptor activator of $\mathrm{NF}-\kappa \mathrm{B}$ ligand expression in osteoblast. J Biol Chem (Online) 2005;280:17497-17506.

25. Samelson EJ, Hannan MT: Epidemiology of osteoporosis. Curr Rheumatol Rep (Online) 2006;8:76-83.

26. Sarkar A, Bhaduri A: Black tea is a powerful chemopreventor of reactive oxygen and nitrogen species: Comparison with its individual catechin constituents and green tea. Biochem Biophys Res Commun (Online) 2001;284:173-178. 